EESTI NSV TEADUSTE AKADEEMIA TOIMETISED. KEEMIA

ИЗВЕСТИЯ АҚАДЕМИИ НАУК ЭСТОНСКОИ ССР. ХИМИЯ

PROCEEDINGS OF THE ACADEMY OF SCIENCES OF THE ESTONIAN SSR. CHEMISTRY $1984,33,1$

Анне ТАЛВАРИ, Кая ТИКС, Х. ЯНКОВСКИИ

удК $551.464 .6 / 7$

\title{
О СОСТАВЕ НЕПОЛЯРНЫХ УГЛЕВОДОРОДОВ В ВОДАХ БАЛТИКИ
}

\author{
(Представил О. Эйзен)
}

Загрязнение морских вод нефтяными углеводородами - установленный факт. В случае значительных нефтяных запрязнений и небольших водоемов определить групповой химический состав проб не представляет труда. Однако проблема осложняется, когда нефтепродукты рассредоточены в малых количествах по большим открытым акваториям. Тогда обычно приходится ограничиваться определением либо отдельных соединений, либо некоторых групп углеводородов, а затем экстраполировать результаты на весь продукт.

Хотя $H$-алканы по сравнению с другими группами углеводородов (разветвленными алканами, цикланами, ароматическими углеводородами) разлагаются в морской воде интенсивнее ['], а с точки зрения токсичности они менее опасны для морской экосистемы, их часто выбирают для характеристики нефтяного загряз:гения из-за легкости газохроматографирования.

Единая методика анализа чрезвычайно сложных по составу нефтяных углеводородов в морских водах до сих пор не разработана. Одни методы (ИК-спектрофотометрия, весовой метод) не позволяют разделять углеводороды на антропогенные и биогенные, другие (газовая хроматография) позволяют лишь предполагать, какое соотношение этих двух типов углеводородов в пробе. В настоящей работе приводятся результаты исследования содержания и состава неполярных углеводородов в водах открытой части Балтийского моря и Финского залива.

\section{Методика анализа}

Пробы морской воды были отобраны во время VI экспедиции научноисследовательского судна «Аю-Даг» в октябре 1977 г. Пробы отбирали с борта судна насосом ОСЕАС (фирма «Интер Оушен», США), который подавал воду в стеклянные бутыли объемом 20 л. Есть мнения [2], что из всех выпускаемых мировым производством глубинных пробоотборников воды на анализ органических соединений только т. н. бутылка Блумера (фирма «Бентос», США) отвечает всем предъявляемым к таким прнборам требованиям. С целью проверки, не загрязняются ли пробы углеводородами через насос OCEAC, воду в бутыли отбирали насосом и вручную с лодки - за 30 м от судна и в месте погружения насоса.

Экстракцию проб проводили на борту судна в экстракторе проточного-типа (фирма «Груббенз», Швеция) с 200 мл н-гексана. Экстракт выпаривали до нескольких миллилитров и хроматографировали на колонке с $\mathrm{Al}_{2} \mathrm{O}_{3}$. 20-миллилитровый $H$-гексановый элюат выпаривали 
почти досуха и доводили объем до 1 мл. Аликвотную часть (обычно 30 мкл) использовали для газохроматопрафического анализа, а остальную часть выпаривали досуха, заменяли н-гексан четыреххлористым углеродом и проводили ИК-анализ на спектрофотометре «Перкин-Эльмер» марки 577. Стандартом сравнения служила смесь н-гексадекана, изооктана и бензена $(37,5: 37,5: 25)$. Газохроматопрафический анализ проводили на хроматографе «Перкин-Эльмер» марки 910. Длина колонки 20 м, диаметр 0,5 мм, неподвижная фаза - OV-17 на твердом носителе (т. н. SCOT-колонка). Температуру колонки повышали с 120 до $270^{\circ}$ со скоростью $3 \%$ мин. Чтобы ввести пробу, 30 мкл гексанового экстракта заливали в алюминиевую капсулу, которую после улетучивания растворителя помещали в инжектор газового хроматопрафа при холодном термостате колонок и затем поднимали температуру колонки $\left.{ }^{3}\right]$. Количественный анализ $н$-углеводородов проводили методом внешней калибровки. Для этого раствор $H$-углеводородов $\mathrm{C}_{16}-\mathrm{C}_{36}$ вводили в хроматограф при тех же условиях, что и анализируемую пробу. Сравнением высот пиков $н$-алканов в исследуемой пробе и стандарте рассчитывали их содержание.

\section{Результаты}

Анализ проб с 18 международных станций, расположенных по т. н. вековому разрезу - десять в Финском заливе и восемь в открытой части Балтийского моря (рис. 1, таблица), показал, что концентрации углево-

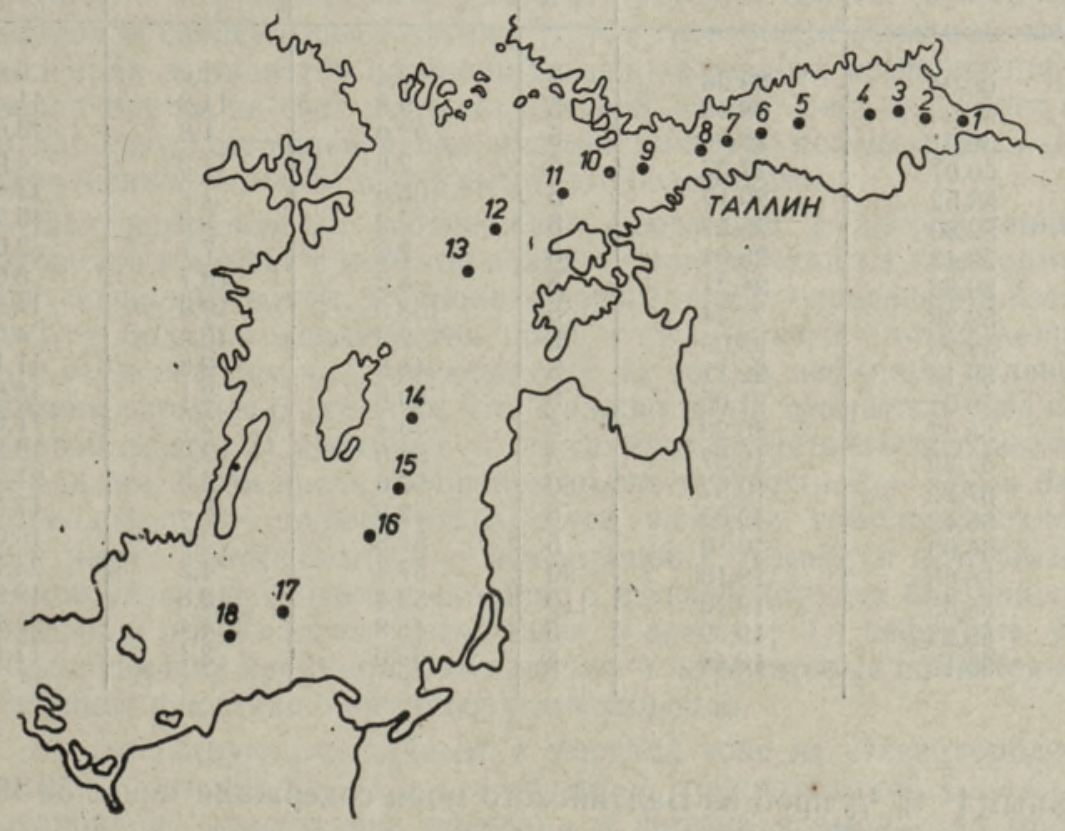

Рис. 1. Схема расположения станций, откуда брали пробы морской воды

дородов в этих двух акваториях составляют в среднем 50,1 и 54,5 мкг/л соответственно, причем в открытом море они рассредотсчены более равномерно. Из десяти проб, взятых из Финского залива, пять имели концентрацию ниже 10 мкг/л, а четыре - ниже 6 мкг/л (рис. 2). Соглас- 

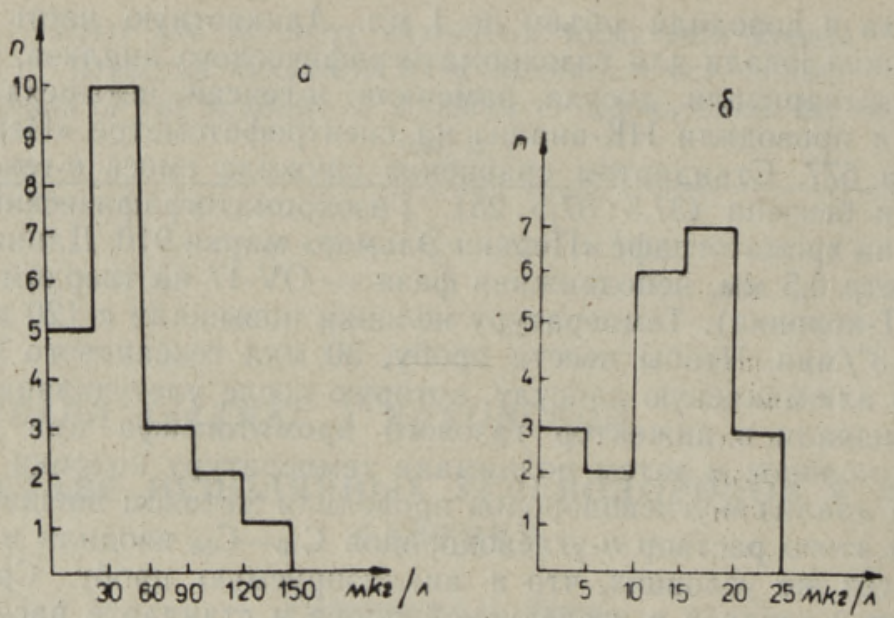

Рис. 2. Гистограммы распределения концентраций суммарных неполярных углеводородов (a) и н-алканов (б) в пробах.

Содержание неполярных углеводородов в водах Балтики

\begin{tabular}{|c|c|c|c|c|c|c|}
\hline \multirow{2}{*}{ 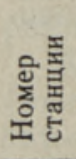 } & \multicolumn{2}{|c|}{ Координаты } & \multirow{2}{*}{ 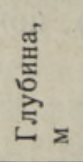 } & \multirow{2}{*}{$\begin{array}{l}\text { Концентрация } \\
\text { неполярных } \\
\text { углеводоро- } \\
\text { дов, мкг/л }\end{array}$} & \multicolumn{2}{|c|}{ Содержание $\boldsymbol{\mu}$-алканов } \\
\hline & широта & долгота & & & $\% \cdot 10$ & $\mathrm{MKr} / \pi$ \\
\hline $\begin{array}{r}1 \\
2 \\
3 \\
4 \\
5 \\
6 \\
7 \\
8 \\
9 \\
10 \\
11 \\
12 \\
13 \\
14 \\
14 \\
15 \\
16 \\
16 \\
16 \\
17 \\
18\end{array}$ & $\begin{array}{l}60,04 \\
60,05 \\
60,07 \\
60,07 \\
59,52 \\
59,50 \\
59,43 \\
59,36 \\
59,30 \\
59,26 \\
59,14 \\
59,01 \\
58,27 \\
57,22 \\
57,22 \\
56,42 \\
56,05 \\
56,05 \\
56,05 \\
55,22 \\
55,15\end{array}$ & $\begin{array}{l}29,08 \\
28,43 \\
28,04 \\
27,23 \\
26,17 \\
25,37 \\
25,01 \\
24,21 \\
23,44 \\
23,09 \\
22,11 \\
21,05 \\
20,20 \\
19,57 \\
19,57 \\
19,52 \\
19,10 \\
19,10 \\
19,10 \\
19,39 \\
16,40\end{array}$ & $\begin{array}{r}5 \\
5 \\
5 \\
5 \\
5 \\
5 \\
5 \\
5 \\
5 \\
5 \\
5 \\
5 \\
5 \\
5 \\
60 \\
5 \\
5 \\
50 \\
110 \\
5 \\
5\end{array}$ & $\begin{array}{r}47,4 \\
9,8 \\
92,0 \\
2,8 \\
103,6 \\
76,2 \\
2,6 \\
5,6 \\
158,0 \\
2,6 \\
44,2 \\
89,6 \\
53,4 \\
56,0 \\
62,0 \\
32,2 \\
51,8 \\
57,4 \\
52,4 \\
45,8 \\
55,0\end{array}$ & $\begin{array}{r}1,9 \\
11,2 \\
1,8 \\
14,3 \\
1,2 \\
2,0 \\
7,7 \\
10,7 \\
0,9 \\
15,4 \\
2,5 \\
2,1 \\
2,2 \\
2,9 \\
3,5 \\
5,3 \\
2,9 \\
4,2 \\
3,8 \\
4,4 \\
3,1\end{array}$ & $\begin{array}{r}9,0 \\
11,0 \\
16,6 \\
4,0 \\
12,4 \\
15,2 \\
2,0 \\
6,0 \\
14,2 \\
4,0 \\
11,1 \\
18,8 \\
11,8 \\
16,2 \\
21,7 \\
17,0 \\
15,0 \\
24,1 \\
19,9 \\
20,1 \\
17,1\end{array}$ \\
\hline
\end{tabular}

но данным [4-6]; ${ }^{2} / 3$ піроб из Балтийского моря содержали менее 50 мкг/л неполярных углеводородов.

Немного завышенные концентрации углеводородов в подповерхностных водах могут быть обусловлены, с одной стороны, медленным микробиологическим разложением углеводородов в условиях низких температур, а с другой - попаданием в пробы взвешенного вещества.

В таблице представлены концентрации $\boldsymbol{H}$-алканов и их процентное содержание в неполярных углеводородах $\mu$ - $\mathrm{C}_{14-38}$. Последнюю величину рассчитывали по формуле 


$$
H-\mathrm{C}_{14-38}=\left[H-\mathrm{C}_{14-38}\right]_{\mathrm{rx}} / \mathrm{C}_{\mathrm{nK}} \cdot 100 \% \text {, }
$$

где $\left[H-\mathrm{C}_{14-38}\right]_{\mathrm{rx}}$ - концентрация $H$-алканов по данным газовой хроматографии; $\mathrm{C}_{\text {ик }}$ - концентрация неполярных углеводородов по данным ИК-спектрофотометрии.

При использовании $\boldsymbol{H}$-алканов в качестве показателя запрязнения вод нефтяными углеводородами не следует забывать об относительно легкой их биодеградации, а также об испаряемости низших гомологов. В этом, очевидно, кроется одна из причин больших несовпадений данных о количественном содержании $н$-алканов в открытом море. Так, по данным газохроматографического метода [7], содержание $H$-алканов в подповерхностных водах Средиземного моря и Атлантического океана составляет от 0,1 до 5,66 мкг/л (5-8\% от суммы выделенных углеводородов); по данным $\left[{ }^{2}\right]$, концентрация $H$-алканов в северо-западной части Атлантического океана не превышает 1 мкг/л при содержании неполярных углеводородов в пределах $0,2-9,3$ мкг/л; по данным [8], водам океанов свойственно низкое содержание $н$-алканов - порядка $1 \%$ от суммы углеводородов.

В наших пробах концентрации $н$-алканов составляют $2-24$ мкг/л. При сопоставлении данных таблицы выяснилось, что между процентным содержанием $н$-алканов и концентрацией в воде неполярных углеводородов существует достоверная отрицательная корреляция $(r=-0,77$ при $P<0,01)$. В то же время установлена корреляция $(r=0,50$ при $P<0,01)$ 'между концентрацией в воде $H$-алканов и содержанием суммарных неполярных углеводородов. По нашему мнению, при увеличении степени загрязненности происходит как бы разбавление $н$-алканов, так как изо- и циклических структур в составе биогенных углеводородов немного, а нафтеноароматические отсутствуют совсем (эти группы углеводородов свойственны нефтям []). На газохроматөграммах отмеченная тенденция выявляется по площади неразделенных компонентов, которая увеличивается за счет подъема нулевой линии (рис. 3). Таким образом, по площади, оставшейся под нулевой линией, можно судить о степени загрязненности пробы нефтяными углеводородами.

Для установления соотношения биогенных и антропогенных углеводородов в пробах с морской водой часто прибегают к газохроматограммам, поскольку метод, в основе которого лежит определение изотопа $\mathrm{C}_{13}$, требует большого количества проб и для нашего случая неприменим. При этом исходят из следующего $\left[{ }^{9}\right]:$ 1) состав нефтяных углеводородов намного сложнее биогенных, что отражается на хроматограмме подъемом нулевой линии; 2) нефтяные углеводороды представлены гомологическими рядами, в том числе изопреноидными алканами $\mathrm{C}_{12}-\mathrm{C}_{22}$, а биогенные углеводороды - только отдельными членами гомологических рядов; 3) в нефти соотношение $н$-углеводородов с четным и нечетным числом атомов углерода близко к единице, а в углеводородах биогенного происхождения преобладают «нечетные» $H$-алканы; 4) нефтяные углеводороды содержат нафтеноароматические и асфальтовые соединения, отсутствующие в составе биогенных углеводородов.

По существующим данным, в морской воде из углеводородов преобладают $\mu$-алканы $\mathrm{C}_{14}-\mathrm{C}_{33}$ с наивысшей концентрацией $\mathrm{C}_{25}-\mathrm{C}_{28}[7,10,11]$. Установлено присутствие пристана и фитана и высказано мнение, что углеводороды из морокой воды более схожи с углеводородами из планктона, чем из осадков $\left[{ }^{10}\right]$.

Из наших анализов вод Балтийского моря выяснилось, что гомологический ряд $H$-алканов состоит из $\mathrm{C}_{15}-\mathrm{C}_{36}$. В некоторых пробах отмечено наличие $H$-алканов до $\mathrm{C}_{38}$. Соотношение $\mathrm{C}_{\text {qет }} / \mathrm{C}_{\text {нечет }} \approx 1$. Пристан и фитан присутствуют в концентрациях, близких к концентрациям $H-C_{17}$ и $\boldsymbol{H}-\mathrm{C}_{18}$. Исключительно все пробы имели повышенное содержание $\boldsymbol{H}$ - $\mathrm{C}_{22}$, 


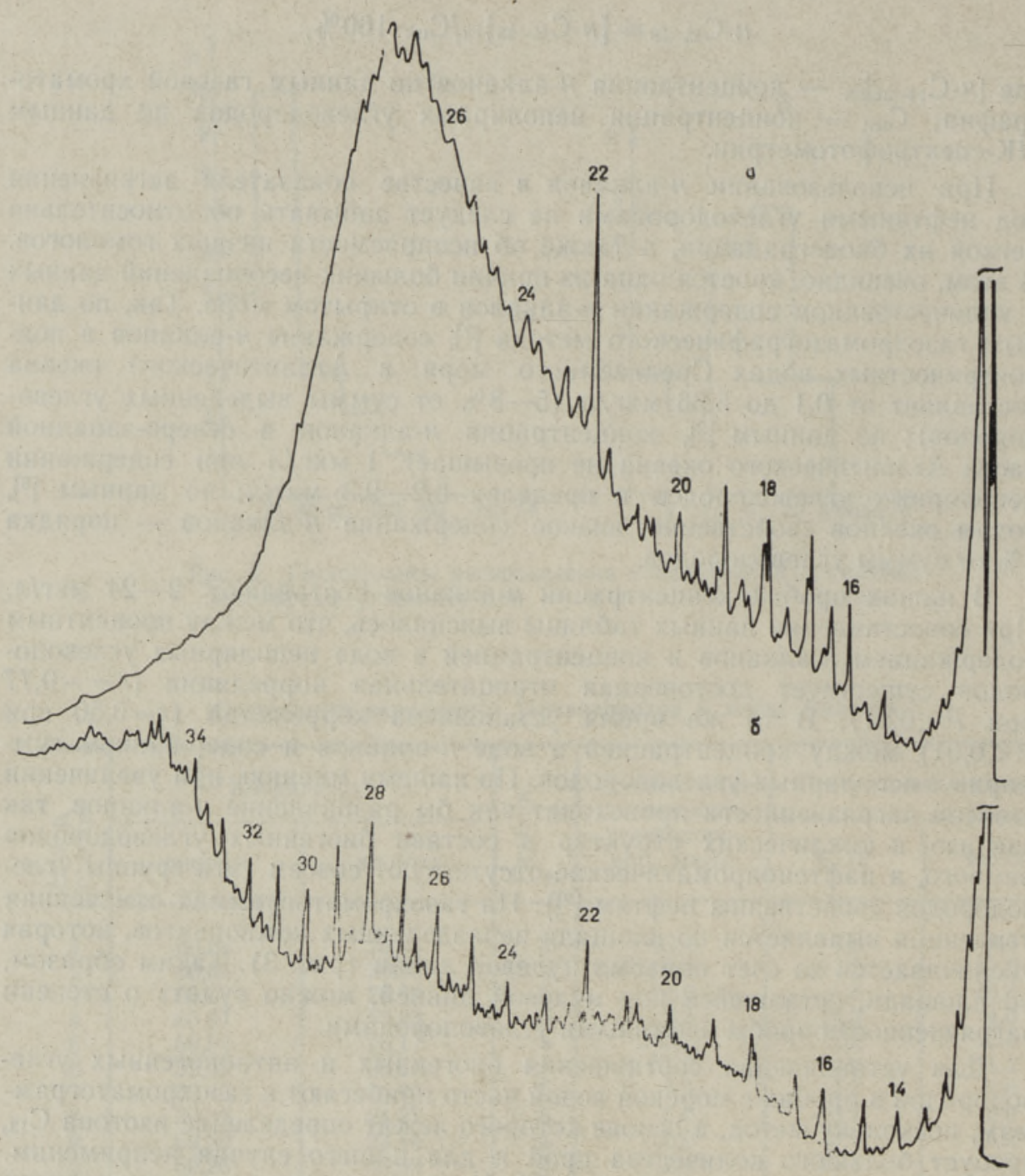

Рис. 3. Газохроматограммы неполярных углеводородов со станций $6(a)$ и 4 (б). Содержание - 76,2 и 2,8 мкг/л соответственно. Номера над пиками означают число атомов углерода в молекуле $н$-алканов.

в некоторых пробах вплоть до $20 \%$ от фракции $н$-алканов. Приблизительно в $1 / 4$ проб присутствовал также углеводород, близкий по времени удерживания к $H$ - $\mathrm{C}_{28}$. Повышенное содержание этих углеводородов не мотло быть артефактом (напр., ложными пиками на газохроматопрамме). Это не раз подтвердили холостые опыты и анализы эталонных омесей. Можно предполагать, что это хенэйкозагексаен и сквален, наличие которых установлено в зоопланктоне и других морских организмах [11]. Из-за отсутствия соответствующих аналитических возможностей структура этих соединений в рамках настоящей работы не установлена. Максимальным было содержание $н$-алканов $\mathrm{C}_{26}-\mathrm{C}_{28}$. Зависимости состава $\boldsymbol{H}$-парафинов от глубины и расстояния от берега не отмечено. Вид газохроматограммы меняется только в зависимости от концентрации неполярных углеводородов в воде, т. е. от степени запрязненности. При этом имеет место: 1) увеличение площади неразделенных пиков; 2) увеличение содержания более низкокипящих соединений во фракции $н$-алканов. 


\section{Выводы}

1. Концентрация неполярных углеводородов в незагрязненных подповерхностных водах Балтийского моря не превышает 10 мкг/л, а в загрязненных районах Финского залива и открытого моря ( $3 / 4$ проб) составляет в ореднем 50,1 и 54,5 мкл/л соответственно.

2. Концентрация $н$-алканов в пробах колеблется в пределах $2-24$ мкг/л, коррелируя с содержанием суммарных неполярных углеводородов $(r=$ $=0,50$ при $P<0,01)$. При высокой степени загрязнения вод процентное содержание $\mu$-алканов падает, а концентрация неполярных углеводородов возрастает $(r=-0,77$ при $P<0,01)$ за счет других групп (изо- и циклических, ароматических), что отражается на хроматограмме более крутым подъемом нулевой линии.

3. представлены гомологическим рядом $\mathrm{C}_{15}-\mathrm{C}_{36}$ с преобладанием $\mathrm{C}_{26}-\mathrm{C}_{28}$ и соотношением $\mathrm{C}_{\text {qет }} / \mathrm{C}_{\text {нечет }} \approx 1$. Из числа изопреноидных углеводородов присутствуют пристан и фитан.

\section{ЛИТЕРАТУРА}

1. ZoBell, C. E. Microbial modification of crude oil in the sea. - In: Proc. Joint. Conf. Prevention and Control of Oil Spills. Amer. Petr. Inst., 1970, 317-326.

2. Keizer, P. D., Gordon, D. C. Jr., Dale, J. Hydrocarbons in Eastern Canadian marine waters determined by fluorescence spectroscopy and gas-liquid chromatography. - J..Fish. Res. Board. Can., 1977, 37, N 3, 347-353.

3. Erhardt, M., Blumer, M. The source identification of marine hydrocarbons by gas chromatography. - Environ. Pollut., 1972, 3, 179-194.

4. Carlberg, S. R. A five-years study of the occurrence of non-polar hydrocarbons (oil) in Baltic waters 1970-75. - Rapp. P.-v. Réun. Cons. int. Explor. Mer., $1977,171,66-68$.

5. Erkomaa, K., Oljypitoisuuksien kartoitustutkimus Suomea ympäröivillä merialueilla vuosina 1971-1972. Helsinki, 1975.

6. Rhode, K.-H. Bestimmung des Olgehalts im Ostseewasser mit der Infrarotspektroskopie. - Seewirtschaft, 1976, 8, N 2, 115-116.

7. Marty, J. C., Saliot, $A$. Hydrocarbons ( $n$-alkanes) in the surface microlayer of seawater. - Deep-Sea Res., 1976, 23, 863-873.

8. Brown, R. A., Huffmann, H. L. Jr. Hydrocarbons in open ocean waters. - Science, $1976,191, \mathrm{~N} 4229,847-849$.

9. Farrington, J. W., Teal, J. M., Parker, L. P. Strategies for Marine Pollution Monitoring. New York, 1976, ch. 1.

10. Blumer, $M$. Dissolved Organic Compounds in Sea Water. Saturated and Olefinic Hydrocarbons and Singly Branched Fatty Acids. Organic Matter in Natural Waters. (Ed. by D. W. Hood.) Inst. Mar. CSU of Alaska, Pub. N 1, 1970.

11. Hardy, R., Mackie, P. R., Whittle, K. J. McIntyre, A. D. Blackman, R. A. A. Occurrence of hydrocarbons in the surface film, sub-surface water and sediment in the waters around the United Kingdom. - Rapp. R.-v. Réun. Cons. int. Explor. Mer., 1977, 171, 61-65.

Ннститут термофизики и электрофизики Академии наук Эстонской ССР

Поступила в редакцию 29/XII 1982

Anne TALVARI, Kaja TIKS, H. JANKOVSKI

\section{LÄANEMERE VEE MITTEPOLAARSETE SUSIVESINIKE KOOSTISEST}

On uuritud Läänemere vee saastumist mittepolaarsete süsivesinikega (MPS), kasutades infrapunast spektrofotomeetriat ja gaasikromatograafiat. Infrapunase spektrofotomeetria andmeil ei ületa MPS-i kontsentratsioon pinnalähedases veekihis (sügavus $1-5 \mathrm{~m}) \quad 10 \mu \mathrm{g} / \mathrm{l}$. $n$-alkaanide sisaldus on gaasikromatograafia andmeil vahemikus 2-24 $\mu \mathrm{g} / \mathrm{l}$, kusjuures korrelatsioon MPS-i summaarse sisalduse ja $n$-alkaanide sisalduse 
vahel on positiivne $(r=0,50, \quad P<0,01)$. Usaldusväärsema negatiivse korrelatsiooni $(r=-0,77, P<0,01)$ põhjuseks $M P S-i$ sisalduse ja $n$-alkaanide protsentuaalse sisalduse vahel MPS-is on autorite arvates asjaolu, et proovi saastumisel süsivesinikega MPS-i sisaldus kasvab peamiselt teiste süsivesinikurühmade arvel (iso- ja tsüklilised, aromaatsed), mis gaasikromatogrammil väljendũb nulljoone järsu tõusuna.

Läänemere vähem saastunud piirkondade $n$-alkaanid on vahemikus $C_{15}-C_{36}$, kusjuures C paarisarv / C paarituarv $\approx 1$. MPS-i koostises esinevad pristaan ja fütaan. Kõige rohkem on $n$-alkaane, mille süsinikuahel on $\mathrm{C}_{26}-\mathrm{C}_{28}$.

\section{Anne TALVARI, Kaja TIKS, H. JANKOVSKI \\ ON THE COMPOSITION OF NON-POLAR HYDROCARBONS OF BALTIC SEA WATER}

Pollution of the Baltic Sea water with non-polar hydrocarbons (NPH) has been investigated using IR-spectrophotometry and gas chromatography. The results of IR-spectrophotometry show that the concentrations of NPH in subsurface water (depth $1-5 \mathrm{~m})$ in the less polluted areas is lower than $10 \mu \mathrm{g} / \mathrm{l}$.

Concentrations of $n$-alkanes obtained using gas chromatography lay within the interval of $2-24 \mu \mathrm{g} / \mathrm{l}$; there exists a positive correlation between the concentrations of $\mathrm{NPH}$ and $n$-alkanes with $r=0.50$ and $P<0.01$. The negative correlation with $r=-0.77$, $P<0.01$ between the concentration of NPH and the content of $n$-alkanes in them is, in the opinion of the authors, due to the fact that by pollution of the samples the concentration of NPH increases mainly on account of other hydrocarbon groups (iso, cyclic, aromatic). On gas chromatograms this is expressed by an increase of the unresolved envelope.

$n$-alkanes of less polluted areas of the Baltic are represented by $\mathrm{C}_{15}-\mathrm{C}_{35}$, $\mathrm{C}_{\text {even }} / \mathrm{C}_{\text {odd }} \approx 1$. The presence of pristane and phytane is established. $\mathrm{C}_{26}-\mathrm{C}_{28}$ are of maximum concentration. 